INCREASED MORTALITY DESPITE SUCCESSFUL MULTIFACTORIAL CARDIOVASCULAR RISK REDUCTION IN HEALTHY MEN : 40-YEAR FOLLOW-UP OF THE HELSINKI BUSINESSMEN STUDY INTERVENTION TRIAL

Strandberg, Timo E.

2018-10

Strandberg , T E , Räikkönen , K, Salomaa , V , Strandberg , A , Kautiainen , H , Kivimäki , M , Pitkälä , K \& Huttunen , J 2018 , ' INCREASED MORTALITY DESPITE SUCCESSFUL MULTIFACTORIAL CARDIOVASCULAR RISK REDUCTION IN HEALTHY MEN : 40-YEAR FOLLOW-UP OF THE HELSINKI BUSINESSMEN STUDY INTERVENTION TRIAL ' , Journal of nutrition, health \& aging , vol. 22 , no. 8 , pp. 885-891 . https://doi.org/10.1007/s12603-018-1099-0

http://hdl.handle.net/10138/253477

https://doi.org/10.1007/s12603-018-1099-0

publishedVersion

Downloaded from Helda, University of Helsinki institutional repository.

This is an electronic reprint of the original article.

This reprint may differ from the original in pagination and typographic detail.

Please cite the original version. 


\title{
INCREASED MORTALITY DESPITE SUCCESSFUL MULTIFACTORIAL CARDIOVASCULAR RISK REDUCTION IN HEALTHY MEN: 40-YEAR FOLLOW-UP OF THE HELSINKI BUSINESSMEN STUDY INTERVENTION TRIAL
}

\author{
T.E. STRANDBERG ${ }^{1,2}$, K. RÄIKKÖNEN ${ }^{3}$, V. SALOMAA ${ }^{4}$, A. STRANDBERG ${ }^{1}$, H. KAUTIAINEN ${ }^{5,6}$, \\ M. KIVIMÄKI ${ }^{1}$, K. PITKÄLÄ ${ }^{1}$, J. HUTTUNEN ${ }^{7}$

\begin{abstract}
1. University of Helsinki and Helsinki University Hospital, Helsinki, Finland; 2. University of Oulu, Center for Life Course Health Research, Oulu, Finland; 3. Institute of Behavioral Sciences, University of Helsinki, Helsinki, Finland; 4. THL-Helsinki, Finland; 5. Unit of Primary Health Care, Kuopio University Hospital, Kuopio, Finland; 6. Folkhälsan Research Centre, Helsinki, Finland; 7. Medical Association Duodecim, Helsinki, Finland. Corresponding author: Timo E. Strandberg, MD, PhD, Professor of Geriatric Medicine, University of Helsinki, Clinicum, Haartmaninkatu 4, PO Box 340, FIN-00029 Helsinki, Finland; email: timo.strandberg@oulu.fi; tel: +358 406724533
\end{abstract}

\begin{abstract}
Objectives: In a 5-year multifactorial risk reduction intervention for healthy men with at least one cardiovascular disease (CVD) risk factor, mortality was unexpectedly higher in the intervention than the control group during the first 15-year follow-up. In order to find explanations for the adverse outcome, we have extended mortality follow-up and examined in greater detail baseline characteristics that contributed to total mortality. Design: Long-term follow-up of a controlled intervention trial. Setting: The Helsinki Businessmen Study Intervention Trial. Participants and Intervention: The prevention trial between 1974-1980 included 1,222 initially healthy men (born 1919-1934) at high CVD risk, who were randomly allocated into intervention $(\mathrm{n}=612)$ and control groups $(n=610)$. The 5-year multifactorial intervention consisted of personal health education and contemporary drug treatments for dyslipidemia and hypertension. In the present analysis we used previously unpublished data on baseline risk factors and lifestyle characteristics. Main outcome measures: 40-year total and cause-specific mortality through linkage to nation-wide death registers. Results: The study groups were practically identical at baseline in 1974, and the 5-year intervention significantly improved risk factors (body mass index, blood pressure, serum lipids and glucose), and total CVD risk by $46 \%$ in the intervention group. Despite this, total mortality has been consistently higher up to 25 years post-trial in the intervention group than the control group, and converging thereafter. Increased mortality risk was driven by CVD and accidental deaths. Of the newly-analysed baseline factors, there was a significant interaction for mortality between intervention group and yearly vacation time $(\mathrm{P}=0.027)$ : shorter vacation was associated with excess 30 -year mortality in the intervention (hazard ratio $1.37,95 \%$ CI $1.03-1.83, \mathrm{P}=0.03$ ), but not in the control group $(\mathrm{P}=0.5)$. This finding was robust to multivariable adjustments. Conclusion: After a multifactorial intervention for healthy men with at least one CVD risk factor, there has been an unexpectedly increased mortality in the intervention group. This increase was especially observed in a subgroup characterised by shorter vacation time at baseline. Although this adverse response to personal preventive measures in vulnerable individuals may be characteristic to men of high social status with subclinical CVD, it clearly deserves further investigation.
\end{abstract}

Key words: Multifactorial prevention, mortality, vacation.

\section{Introduction}

Unexpected findings in the 5-year intervention period and the 15-year mortality follow-up of the Helsinki multifactorial primary prevention trial (Helsinki Businessmen Study, HBS (1-4)) seemed to defy current knowledge as to the treatment of cardiovascular risk factors in middle-aged men. Despite significant decreases in traditional cardiovascular risk factors during the intervention period, 1974-1980, mortality up to 1990 was $46 \%$ higher in the intervention group than in the control group (2). This result has puzzled investigators in the field (5-8), especially as no plausible explanation for such results emerged from previous analyses. For example, the multidrug treatments - including cholesterol and blood pressure lowering medications -- used in the intervention group could not be related to excess mortality $(1,2)$. It has, however, been speculated that intense lifestyle intervention might have had

psychologically detrimental effects on the participants $(2,7)$. If so, the results of this particular trial would have broader implications for multifactorial prevention in healthy middleaged men.

The aim of the current report is to explore possible explanations for the unexpected finding. Because mortality difference seemed to be increasing even 10 years after the HBS trial (2) we have now extended the mortality followup to 40 years (through 31 December, 2014). We have also re-examined original data along with formerly neglected baseline information on lifestyle characteristics and related them to the long-term mortality. These previously unanalyzed factors included vacation time -- which in the Multiple Risk Factor Intervention Trial (MRFIT, 9) was inversely related to follow-up mortality -- working hours that have been related to cardiovascular disease (10), and sleep duration that has been related to total mortality (11). The analyses are hypothesis- 


\section{0-YEAR FOLLOW-UP OF THE HELSINKI BUSINESSMEN STUDY INTERVENTION TRIAL}

generating, but may give new perspectives to intensive individual health education in healthy middle-aged people at risk of CVD.

\section{Methods}

\section{Study Design, Participants and Procedures}

Details and structure of the HBS have been described in previous reports (1-4). In brief, participants of the prevention trial were recruited from healthy volunteers from a background population of 3,490 businessmen and executives born between 1919-1934 who had attended health check-ups with risk factor measurements and received some health education during 1964-1973. In 1974-1975, healthy volunteers from this population with no clinical CVD, no diabetes, no regular drug treatment for CVD risk factors but at least one cardiovascular risk factor (smoking, hypertension, hypercholesterolemia, hypertriglyceridemia, glucose intolerance, overweight) were randomly allocated to form an intervention group $(n=612)$ and a control group ( $\mathrm{n}=610)$ (1). According to the traditional risk factor levels, the groups were well balanced at baseline indicating successful randomisation (1). The average number of CVD risk factors in both groups was 2.1.

During the five trial years (1974-1980), the members of the intervention group were planned to visit the investigators every fourth month, whereupon they received individual - oral and written -- health instructions according to contemporary concepts of preventive medicine. They were given information about their risk factors and repeatedly advised to engage in aerobic physical activity; consume a healthy diet emphasising intake of vegetables, fruits, and whole grains, and limiting intake of saturated fats, sweets, and sugar-sweetened beverages; maintain a healthy weight; and stop smoking. In addition, antihypertensive drugs (mainly beta-blockers and diuretics) and lipid-lowering drugs (mainly probucol and clofibrate; statins did not exist at that time) were frequently used, when health education alone was not sufficiently effective (1). The members of the control group received standard health care and were not seen by the investigators.

Intervention led to a substantial reduction in most risk factors in the intervention group (1), and in the coronary risk score for hard criteria (46\% reduction) calculated according to Keys et al (12). At the end of the trial in 1979-1980, the prevalence of participants on antihypertensive treatment was $32 \%$ in the intervention group and $15 \%$ in the control group $(\mathrm{P}<0.05$ between groups). The corresponding figures for lipid-lowering treatment were $37 \%$ and $0 \%$, respectively $(\mathrm{P}<0.05$ between groups).

At the end of the trial in 1979-1980, all survivors were re-examined, where after they have all been treated by their own physicians as needed.

The first post-trial evaluation using questionnaires and laboratory examinations was performed five years later in 1985-1986 (4). By that time the risk-factor differences (except mean body mass index) between the intervention and control groups had largely levelled off. The prevalence of participants on antihypertensive treatment was $27 \%$ in the intervention group and 22\% in the control group. The corresponding figures for lipid-lowering treatment were negligible, $2.4 \%$ and $1.8 \%$, respectively. The prevalencies of drug treatments were no more significantly different five years post-trial.

For the present analyses, information about total mortality of the study population up to December 31, 2014, was extracted from the National Population Information System, which keeps registry of all Finnish citizens. According to the register, assessment of vital status is very reliable for people having their permanent place of residence in Finland (over 95\% of the present cohort) irrespective whether they die in Finland or abroad. Moreover, the assessment of the vital status is also reliable for Finnish citizens living permanently abroad. Causes of death, analysed up to 31 December, 2004, were determined from the nationwide computerized Cause-of-Death Register of Statistics Finland in which trained nosologists code the causes of death. The causes were categorised in 6 groups: cardiac, stroke, other CVD, cancer, violent (accidents and suicides separately), and other causes.

In the present analyses, we have also used previously unpublished data from questionnaires filled in by the participants at baseline in 1974-75. These questionnaires included data about lifestyle (vacation, sleep, work), and the men were also asked questions on self-rated health (SRH) and physical fitness on a 5-point scale ("very good", "good", "average", "fairly poor", "very poor"). This wording of SRH was similar to that used in the Whitehall study (13). Because there were very few men perceiving their status as "very poor', they were combined with 'fairly poor' as 'poor'. The participants were asked to report their usual working hours (median $47 \mathrm{~h} /$ week, interquartile range [IQG] 40-52), vacation time (median 30 working days/year, IQR 21-30) and sleep duration (median $50 \mathrm{~h} /$ week, IQR 48-55). In the intervention and control groups 154 and 166 men, respectively, reported having $<21$ working days of vacation annually. In the analyses, this cutpoint, representing the 25 th percentile, was used to categorise vacation time.

During the 1970s when the trial was performed, the patients consented to the trial but no formal ways to register the trial were available nor required. All follow-up results of the trial have been published before 1997 when US Congress passed law (FDAMA) requiring trial registration. The extended followup of the cohort was approved by the ethical committee of the Department of Medicine, Helsinki University Central Hospital and was registered as ClinicalTrials.gov identifier NCT02526082.

\section{Statistical Analysis}

NCSS statistical software (www.ncss.com) was used for the analyses. In the analyses, $t$-tests, nonparametric tests and analyses of covariance (ANCOVA) were used where 


\section{THE JOURNAL OF NUTRITION, HEALTH \& AGING@}

appropriate to compare continuous variables between the intervention and control group. Chi-square and trend tests were used to compare proportions. Differences in mortality curves were analysed with the log rank test. Requirements for proportional hazards were checked and hazard ratios (HR) with their $95 \%$ confidence intervals (CI) for mortality were calculated using Cox proportional hazards regression with covariates. Besides the 40-year follow-up, we also analysed causes of deaths during the first 30 years of follow-up, because mortality curves were parallel after that thus diluting intervention effects. To study whether work, sleep or vacation time would modify the intervention effect, an interaction term (intervention-control group* time) was included in the model. A flexible parametric proportional-hazards model was fitted using restricted cubic splines. In statistical analyses 2-tailed tests were used and $\mathrm{P}$ values $<0.05$ were taken as statistically significant.

\section{Results}

\section{In-trial changes}

Baseline risk factors and lifestyle characteristics of the two groups in year 1974 are shown in Table 1. This comparison shows that the groups were well balanced at baseline. Furthermore, there was no significant difference in the distributions of self-rated health $(\mathrm{P}=0.81)$ or self-rated physical fitness $(\mathrm{P}=0.54)$ between the intervention and control groups at baseline. The principal risk factors after the 5-year intervention period (between 1974-1980) are shown in Table 2. Body mass index (BMI), blood pressure, serum lipids and onehour glucose were significantly improved in the intervention group as compared to the control group. However, the absolute reductions were not large, for example, BMI was 3\% lower, systolic blood pressure 5\% lower, and cholesterol $6 \%$ lower in the intervention than in the control group at end of the intervention. There was no significant difference in smoking, because it was reduced both in the intervention and control groups.

\section{Mortality during the 40-year follow-up}

Total mortality data during various phases of follow-up have been reported earlier (1-4). During the 5-year intervention period there were 10 and 5 deaths in the intervention and control groups, respectively $(\mathrm{HR}=2.00,95 \% \mathrm{CI}, 0.63-6.66, \mathrm{P}$ $=0.3$ ). During the first 15 years from start of the intervention there were significantly more deaths in the intervention than in the control group (67 vs. $46, \mathrm{HR}=1.45,95 \% \mathrm{CI}, 1.01-2.08, \mathrm{P}$ $=0.048$ ). Crude mortality curves for the entire 40-year followup are shown in Fig 1. The difference between the groups is no longer statistically significant (434 vs 409 deaths, HR (Keys adjusted) 1.08 (95\% CI: 0.94 to 1.23 ) $\mathrm{P}=0.28$ ), because the mortality curves have converged for several years, but a "bulge" between curves during 10 to 25 years of follow-up can be discerned (Fig. 1).
Table 1

Comparison of the study groups at baseline in 1974-1975

\begin{tabular}{|c|c|c|c|}
\hline Variable & $\begin{array}{c}\text { Intervention } \\
\text { group }(n=612)\end{array}$ & $\begin{array}{c}\text { Control group } \\
(\mathbf{n}=\mathbf{6 1 0})\end{array}$ & $\begin{array}{c}P \text { value } \\
\text { between groups }\end{array}$ \\
\hline Age, years & $48(4)$ & $48(4)$ & 0.75 \\
\hline Body mass index, $\mathrm{kg} / \mathrm{m} 2$ & $26.4(2.9)$ & $26.6(2.8)$ & 0.30 \\
\hline $\begin{array}{l}\text { Reported weight gain from } \\
25 \text { years of age to } 1974, \mathrm{~kg}\end{array}$ & $11.5(8.5)$ & $11.4(8.3)$ & 0.91 \\
\hline Resting heart rate/min & $66(11)$ & $66(12)$ & 0.54 \\
\hline \multicolumn{4}{|l|}{ Blood pressure, $\mathrm{mmHg}$} \\
\hline Systolic & $148(18)$ & $146(19)$ & 0.17 \\
\hline Diastolic & $96(11)$ & $94(11)$ & 0.01 \\
\hline $\begin{array}{l}\text { Serum cholesterol, } \\
\mathrm{mmol} / \mathrm{L}^{*}\end{array}$ & $6.5(1.0)$ & $6.5(1.1)$ & 0.63 \\
\hline $\begin{array}{l}\text { Serum triglycerides, } \\
\mathrm{mmol} / \mathrm{L}\end{array}$ & $1.8(1.0)$ & $1.8(1.0)$ & 0.96 \\
\hline 1-h blood glucose, $\mathrm{mmol} / \mathrm{L}$ & $7.4(2.3)$ & $7.5(2.3)$ & 0.22 \\
\hline $\begin{array}{l}\text { Alcohol consumption, g/ } \\
\text { week }\end{array}$ & $185(184)$ & $168(146)$ & 0.17 \\
\hline Smokers, n (\%) & $239(39)$ & $226(37)$ & 0.56 \\
\hline Keys' risk score, $\%+$ & $2.6(2.0)$ & $2.5(2.0)$ & 0.34 \\
\hline Work time, hours/week & $49(10)$ & $48(9)$ & 0.01 \\
\hline Sleep, hours/week & $50(7)$ & $51(6)$ & 0.08 \\
\hline Vacation time, days/year & $27(10)$ & $26(10)$ & 0.37 \\
\hline
\end{tabular}

Figure 1

Total mortality in the study groups during the 40-year follow-up

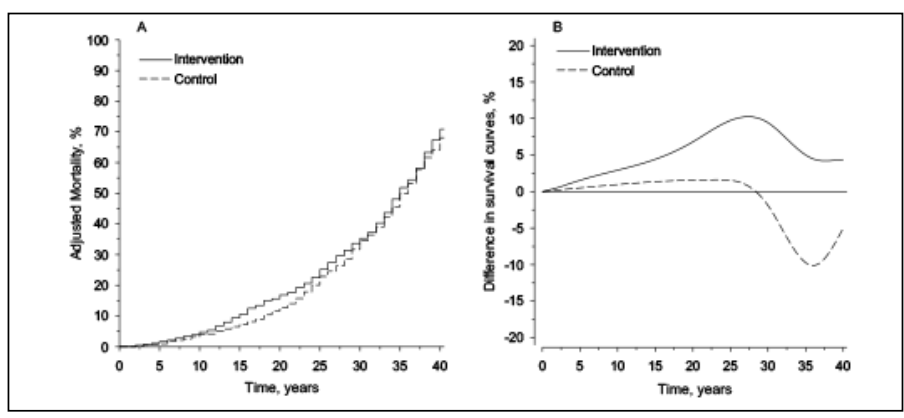

Intervention group = solid line; Control group= dotted line; Panel A: Adjusted cumulative mortality. Panel B: Difference in survival curves between the intervention and control groups.

Because mortality converged with increasing follow-up, causes of death were analysed during the first 30 years, up to 31 December, 2004, and could be retrieved for 221 and 210 deaths in the intervention and control groups, respectively (Table 3). Age-adjusted HR was 1.23 (95\% CI 0.85-1.80, $\mathrm{P}=0.27$ ) for cardiac deaths, and 2.56 (95\% CI, 1.13-5.82, $\mathrm{P}=$ 0.025 ) for violent deaths (including accidents), so that a higher mortality characterized the intervention group. Perusal of death certificates with narratives suggested that it was impossible in most cases of accidental deaths to rule out a potential disease attack as the primary cause. 
Table 2

Risk factors at end of 5-year intervention in 1979-1980

\begin{tabular}{lccc}
\hline Variable & $\begin{array}{c}\text { Intervention } \\
\text { group }(\mathbf{n = 5 7 5})\end{array}$ & $\begin{array}{c}\text { Control } \\
\text { group }(\mathbf{n = 5 8 0})\end{array}$ & $\begin{array}{c}\text { P value } \\
\text { between groups }\end{array}$ \\
\hline Body mass index, $\mathrm{kg} / \mathrm{m} 2$ & $26.2(2.9)$ & $26.9(2.8)$ & $<0.0001$ \\
Blood pressure, $\mathrm{mmHg}$ & & & \\
Systolic & $135(13)$ & $142(17)$ & $<0.0001$ \\
Diastolic & $88(9)$ & $91(10)$ & 0.002 \\
Serum cholesterol, mmol/L* & $6.2(0.9)$ & $6.6(1.1)$ & $<0.0001$ \\
Serum triglycerides, mmol/L & $1.6(0.9)$ & $1.8(1.1)$ & $<0.0001$ \\
1-h blood glucose, $\mathrm{mmol} / \mathrm{L}$ & $7.7(2.6)$ & $7.9(2.5)$ & 0.003 \\
Alcohol consumption, g/week & $136(128)$ & $144(146)$ & 0.6 \\
Smokers, $\mathrm{n}(\%)$ & $163(28.5)$ & $171(29.6)$ & 0.7 \\
\hline
\end{tabular}

* Concentrations corrected to values with modern methods.

\section{Figure 2}

Adjusted total mortality curves according to baseline vacation time in the intervention (Panel A) and control (Panel B) groups during the 40-year follow-up

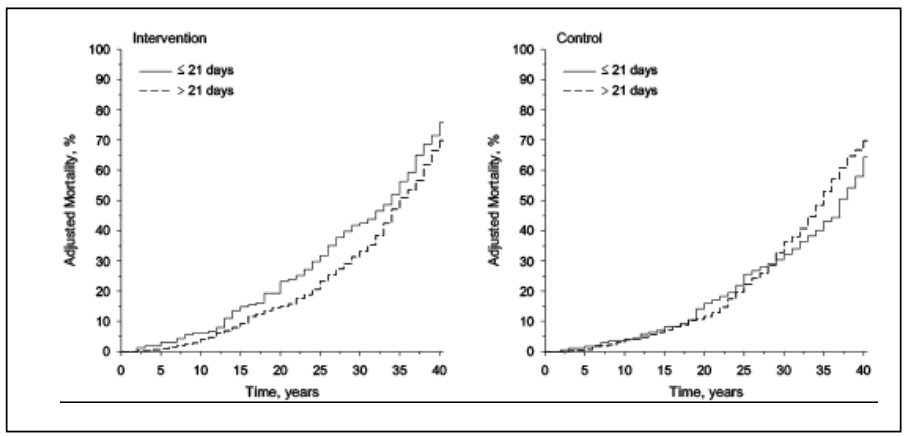

Solid line $=$ annual vacation $<21$ days; dotted line $=$ annual vacation $>21$ days.

\section{Subgroup analyses}

Preliminary analyses showed that of the reported baseline work, vacation and sleep times, only shorter yearly vacation time separated the study groups, and adjusted interaction between group and annual length of vacation time (but not with work and sleep time) was significant $(\mathrm{P}=0.013)$. Crude 40 -year mortality curves (Fig. 2) according to annual vacation time (cutpoint 21 working days) were different between intervention (HR 1.17, 95\% 0.94 to $1.45 ; \mathrm{P}=0.15$ ) and control groups (HR $0.86,95 \%$ CI 0.69 to $1.07 ; \mathrm{P}=0.18)$. If follow-up was restricted to 30 years, the respective HRs were 1.37 (95\% CI 1.03 to 1.83; $\mathrm{P}=0.03$ ) for intervention group, and 0.90 (95\% CI 0.66 to 1.22; $\mathrm{P}=0.50)$ for the control group.

Multivariate analyses were performed to resolve whether the shorter annual vacation time was an independent predictor of 40-year total mortality. As a covariate we used the baseline log-transformed Keys' risk score (includes age, smoking, BMI, cholesterol, and systolic blood pressure), which predicted 40-year mortality (HR per SD $1.44,95 \%$ CI 1.31 to 1.58 , $\mathrm{P}<0.001)$. In this analysis there was a significant interaction between the treatment group and vacation time (HR 1.61, 95\% CI 1.06 to $2.47, \mathrm{P}=0.027$ ), suggesting that excess mortality in the intervention group was modified by vacation time. Annual differences in mortality up to 30 years according to vacation time ( $<21$ days vs $>21$ days) in the intervention and control groups are summarised in Fig. 3 demonstrating the constant difference between the 2 groups starting early and widening during the long-term follow-up.

\section{Figure 3}

Cumulative difference between shorter and longer vacation in the intervention and control groups during 30-year follow-up

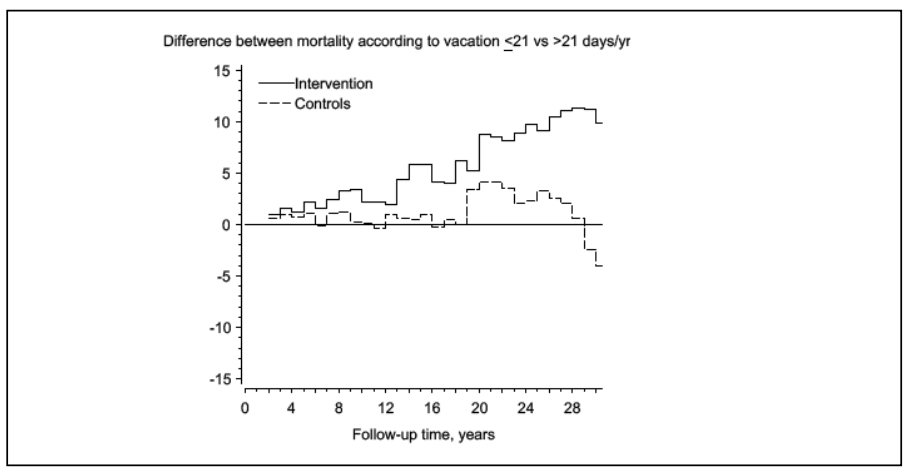

Finally, we compared baseline characteristics of the men with short vs longer annual vacation time (men in both groups combined). Men with short vacation worked more $(\mathrm{P}<0.001)$, slept less $(\mathrm{P}=0.04)$, and had worse self-rated health $(\mathrm{P}=0.018)$ than men with longer vacation, but there were no significant differences in BMI, CVD risk factors (smoking, blood pressure, serum lipids), and alcohol consumption.

\section{Discussion}

Despite improvements of cardiovascular risk factors during intervention, multifactorial primary prevention was associated with more deaths during the first two decades after the start of the trial among middle-aged high-risk men. The forms of the mortality curves in the control and intervention groups are in keeping with a harm induced by the intervention, peaking at 15-20 years post-trial and weakening thereafter. Excess deaths seemed to be mainly due to cardiac and accidental deaths. The significant interaction between the intervention group and vacation time further suggests that the harm induced by intervention was concentrated in a vulnerable subgroup of men characterized by shorter yearly vacation time. We speculate that adverse psychological effects of intervention in certain individuals are at least partly the explanation for the excess deaths.

Both the American Heart Association policy statement for CVD prevention at worksites (14), and the European 2016 Clinical Guideline for CVD prevention in clinical practice (15) recommend stress management/reduction for individuals at high CVD risk or with an established CVD. This was not part of the concepts of preventive medicine used in the multifactorial 


\section{THE JOURNAL OF NUTRITION, HEALTH \& AGINGC}

Table 3

Numbers and causes of death up during the first 30-year follow-up in the study groups

\begin{tabular}{lllll}
\hline Variable & Intervention group $(\mathbf{n}=\mathbf{6 1 2})$ & Control group $(\mathbf{n = 6 1 0})$ & HR $(\mathbf{9 5 \%} \mathbf{C I}) *$ & P value between groups \\
\hline All cardiovascular & 91 & 78 & $1.17(0.87-1.59)$ & 0.30 \\
- Cardiac & 70 & 58 & $1.22(0.86-1.72)$ & 0.27 \\
- Stroke & 13 & 10 &.. & \\
- Other cardiovascular & 8 & 10 &.. & \\
Neoplasms & 66 & 83 & $0.88(0.65-1.19)$ & 0.41 \\
Violent & 20 & 8 & $2.56(1.13-5.82)$ & 0.025 \\
- Accidents & 17 & 5 &.. & \\
-Suicides & 3 & 3 &.. & \\
Other & 44 & 41 &.. & \\
Total & 256 & 236 & $1.06(0.88-1.28)$ & 0.53 \\
\hline
\end{tabular}

*HR indicates hazard ratio of age-adjusted cause-specific mortality (with $95 \%$ confidence interval)

prevention during the late 1970s. Prospective studies have linked coronary heart disease with various psychosocial factors. These include work, home/marital, and other acute or chronic stressors (16-19), various personality characteristics, emotional factors and mood disorders $(20,21)$, shorter vacation (9), and longer work time (10). Even a doctor's round in hospital may acutely increase myocardial infarcts (22), and daily hassles predict mortality (23).

Already during the 1990s various pathogenetic mechanisms for these associations were presented, including stress-induced adverse changes in risk factors (lipids, fibrinogen, coagulation factors $(24,25))$, and direct effects on factors related to myocardial infarction and sudden death, such as endothelial function (26) and cardiac autonomic control (27). The concept of allostatic load $(28,29)$, i.e. long-term environmental challenge leading to chronic fluctuations in bodily responses - with a growing list of extra- and intracellular mediators (30) -- may help to understand further the pathways to disease onset and poor outcomes. In the cardiovascular system this might involve repeated bouts of endothelial damage and accelerating atherosclerosis through neuroendocrine mediators as well as inflammatory, hemostatic, and autonomic processes that trigger a cardiac event in individuals with atherosclerotic burden (31). It is also evident that these middle-aged men with CVD risk factors - albeit clinically healthy - already had subclinical CVD and advanced lesions in their coronary tree (32). Sudden cardiac deaths may also mask as accidental deaths, when due to fatal arrhythmia.

If omission of stress management in the intervention encouraged participants to ignore chronic stress as part of healthy lifestyle, this could have long-term adverse effects. One may argue that if psychological factors have true pathogenetic influence, the adverse effect on mortality should only be seen during the intervention period. However, the intervention period lasted for 5 years, and effects of psychological influence may last longer, in particularly, if inducing an attitude that management of body mass index, blood pressure, serum lipids and glucose is enough to minimize CVD risk. For example, in the study of Rosengren et al (33), stressful life events were associated with mortality during 7 years' follow-up, and in the study of Carroll et al (34) up to 16 years of follow-up. Similarly to a positive legacy, also a negative one may take place longterm.

Our speculations must not be taken to signify that individual health education as such is harmful. Although Cochrane reviews have suggested limited benefit from multifactorial primary prevention $(35,36)$, several individual studies using personal lifestyle modifications have definitely shown benefit in the prevention of CVD $(37-40)$ or diabetes $(41,42)$. On the other hand, despite the beneficial effect on several CVD risk factors in the Look AHEAD (Action for Health in Diabetes) trial, CVD events were not reduced during median follow-up of almost 10 years (43). Modern preventive medications, such as statins, were used in both groups of the Look AHEAD trial, and overall, target populations in these trials have been quite different from the present one, which may be the decisive factor.

Turning to a more speculative area in the search of explanations, studies in nonhuman primates have revealed various effects of social position on biological functioning and health (44). Analogously, might the change of a dominant individual to a subordinate status in health care have made some executives more vulnerable to psychological distress? Moreover, feelings of a personal failure to modify lifestyle according to instructions - such as in the current intervention trial - can be especially frustrating for individuals concerned of their health. Indeed, shorter vacation in our cohort was associated with worse self-rated health, and tended to be associated with some mental components of quality of life 


\section{0-YEAR FOLLOW-UP OF THE HELSINKI BUSINESSMEN STUDY INTERVENTION TRIAL}

(45). Also modern stress research has emphasized the effect of perceived - subjective, not objective - amount of stress in the pathway to health disorders $(46,47)$.

The negative psychological effects of personal intervention were obviously not counteracted by the weak methods available for treatment of CVD risk factors during the 1970s (non-statin drugs for hyperlipidemia, beta-blockers for hypertension). This is further emphasized by the relatively high baseline risk factor levels (mean systolic blood pressure $148 \mathrm{~mm} \mathrm{Hg}$, mean plasma cholesterol $6.5 \mathrm{mmol} / \mathrm{L}$ ). Therefore, at the mean age of 48 years subclinical CVD was likely to be present and much more efficient prevention would have been needed.

\section{Limitations}

Obviously, male sex and social class distribution limit generalizability of the study, but there are also other important points to discuss. Baseline information on personal characteristics is sparse - after all the primary aim was not to study their influence -- and the discussion of their influence is necessarily speculative. However, we had information of vacation time, which in another multifactorial trial was associated with mortality (7). Also the play of chance must be taken into account in a relatively small trial. Still, the study groups were comparable at baseline, the mortality difference at its peak was highly statistically significant, and above all, the results were quite opposite to the one the investigators were hoping for.

Finally, the study and its results may be questioned, because it was performed 40 years ago. However, while preventive drug treatment has greatly developed during the last decades, the methods and aims of individual lifestyle modification exercise, diet, weight reduction -- have largely remained the same.

\section{Conclusions}

The paradoxical increase of mortality after successful multifactorial prevention is provocative and may be neglected as an anomalous result. Nevertheless, we think that it is worthwhile to present these post-hoc analyses in a hypothesisgenerating manner as they closely relate to the long-term debate and questions about the value of early intervention and risk-benefit ratios of intervention methods in primary prevention $(48,49)$. The results raise the possibility that submitting middle-aged men at high risk of CVD to personal lifestyle modification - but with only modest concomitant risk factor changes - might for some men be harmful. Because personal lifestyle modifications are traditionally (and at times aggressively) advocated in primary prevention of CVD irrespective of the grade of subclinical disease, better recognition and better treatment strategies of vulnerable individuals clearly calls for further study.

Funding: Financial support was received from Gustaf och Victoria Frimurarestiftelse, the Helsinki and Uusimaa Hospital District (HUS), and the Academy of Finland (grant
311492). The funders had no role in the design or conduct of the study; collection, management, analysis, and interpretation of the data; or preparation, review, or approval of the manuscript.

Conflict of Interest: All authors (Strandberg TE, Räikkönen K, Salomaa V, Strandberg A, Kautiainen H, Kivimäki M, Pitkälä K, Huttunen J) declare no conflict of interest related to this article.

Ethical Standards: The follow-up described here complies with the current laws of Finland.

\section{References}

1. Miettinen TA, Huttunen JK, Naukkarinen V, et al. Multifactorial primary prevention of cardiovascular diseases in middle-aged men. JAMA 1985;254:2097-2102.

2. Strandberg TE, Salomaa VV, Naukkarinen VA, Vanhanen HT, Sarna SJ, Miettinen TA. Long-term mortality after 5-year multifactorial primary prevention of cardiovascular diseases in middle-aged men. JAMA 1991;266:1225-1229.

3. Strandberg TE, Salomaa VV, Vanhanen HT, Naukkarinen V, Sarna S, Miettinen TA. Mortality in participants and non-participants of a multifactorial prevention study of cardiovascular diseases: a 28 year follow up of the Helsinki Businessmen Study. Br Heart J 1995;74:449-454

4. Strandberg TE, Salomaa V, Strandberg AY, et al. Cohort Profile: The Helsinki Businessmen Study (HBS). Int J Epidemiol 2016;45:1074-1074h.

5. Paul O, Hennekens $\mathrm{CH}$. The latest report from Finland. A lesson in expectations. JAMA 1991;266:1267-1268.

6. Oliver MF. Doubts about preventing coronary heart disease. BMJ 1992;304:393-394

7. Anonymous. Should clinical trials carry a health warning? (Editorial) Lancet 1991;338:1495-6.

8. Stamler J. Lessons from the Helsinki Multifactorial Primary Prevention Trial. Nutr Metab Cardiovasc Dis 1995;5:1-5.

9. Gump BB, Matthews KA. Are vacations good for your health? The 9-year mortality experience after the multiple risk factor intervention trial. Psychosom Med 2000;62:608-12.

10. Kivimäki M, Jokela M, Nyberg ST, et al, IPD-Work Consortium. Long working hours and risk of coronary heart disease and stroke: a systematic review and meta-analysis of published and unpublished data for 603,838 individuals. Lancet 2015;386(10005):1739-46

11. Kripke DF, Garfinkel L, Wingard DL, Klauber M, Marler M. Mortality associated with sleep duration and insomnia. Arch Gen Psychiatry 2002;59:131-36.

12. Keys A, Aravanis C, Blackburn H, et al. Probability of middle-aged men developing coronary heart disease in five years. Circulation 197245:815-828.

13. Marmot MG, Shipley MJ. Do Socioeconomic differences in mortality persist after retirement? 25 year follow up of civil servants from the first Whitehall study. BMJ 1996;313:1177-1180.

14. Carnethon M, Whitsel LP, Franklin BA, et al. American Heart Association Advocacy Coordinating Committee; Council on Epidemiology and Prevention; Council on the Kidney in Cardiovascular Disease; Council on Nutrition, Physical Activity and Metabolism. Worksite wellness programs for cardiovascular disease prevention: a policy statement from the American Heart Association. Circulation 2009;120:1725-41. doi: 10.1161/CIRCULATIONAHA.109.192653.

15. Piepoli MF, Hoes AW, Agewall S,et al; Authors/Task Force Members. European Guidelines on cardiovascular disease prevention in clinical practice: The Sixth Joint Task Force of the European Society of Cardiology and Other Societies on Cardiovascular Disease Prevention in Clinical Practice (constituted by representatives of 10 societies and by invited experts) Developed with the special contribution of the European Association for Cardiovascular Prevention \& Rehabilitation (EACPR). Eur Heart J 2016;37:2315-81.

16. Rosengeren A, Hawken S, Öunpuu S, et al for the INTERHEART investigators. Association of psychosocial risk factors with risk of acute myocardial infarction in 11119 cases and 13648 controls from 52 countries (the INTERHEART study): casecontrol study. Lancet 2004;364:953-62.

17. Rozanski A, Blumenthal JA, Davidson KW, Saab PG, Kubzanski L. The epidemiology, pathophysiology, and management of psychosocial risk factors in cardiac practice. J Am Coll Cardiol 2005;45:637-51

18. Kivimäki M, Nyberg ST, Batty GD, et al; IPD-Work Consortium. Job strain as a risk factor for coronary heart disease: a collaborative meta-analysis of individual participant data. Lancet 2012;380:1491-7.

19. Arnold SV, Smolderen KG, Buchanan DM, Li Y, Spertus JA. Perceived stress in myocardial infarction: long-term mortality and health status outcomes. J Am Coll Cardiol 2012;60:1756-63. doi: 10.1016/j.jacc.2012.06.044.

20. Evans DL, Charney DS, Lewis L, et al. Mood disorders in the medically ill. Biol Psychiatry 2005;58:175-89.

21. Smyth A, O'Donnell M, Lamelas P, Teo K, Rangarajan S, Yusuf S; INTERHEART Investigators. Physical Activity and Anger or Emotional Upset as Triggers of Acute Myocardial Infarction: The INTERHEART Study. Circulation 2016;134:1059-1067

22. Järvinen KAJ. Can ward rounds be a danger to patients with myocardial infarction. Br Med J 1955;1;318-320.

23. Jeong YJ, Aldwin CM, Igarashi H, Spiro A 3rd. Do hassles and uplifts trajectories predict mortality? Longitudinal findings from the VA Normative Aging Study. 


\section{THE JOURNAL OF NUTRITION, HEALTH \& AGINGC}

Behav Med 2016:39:408-19.

24. Björntorp P. Hypothesis. Visceral fat accumulation: the missing link between psychosocial factors and cardiovascular disease? J Intern Med 1991;230:195-201.

25. Muldoon MF, Herbert TB, Patterson SM, Kameneva M, Raible R, Manuck SB Effects of acute psychological stress on serum lipid levels, hemoconcentration, and blood viscosity. Arch Intern Med 1995; 155:615-620.

26. Yeung AC, Vekhstein VI, Krantz DS, et al. The effect of atherosclerosis on the vasomotor response of coronary arteries to mental stress. N Engl J Med 1991;325:1551-6.

27. Kawachi I, Sparrow D, Vokonas PS, Weiss ST. Decreased heart rate variability in men with phobic anxiety (Data from the Normative Aging Study). Am J Cardio 1995; 75:882-885.

28. McEwen BS. Protective and damaging effects of stress mediators. N Engl J Med 1998;338:171-178

29. Karatsoreos IN, McEwen BS. Psychological allostasis: resistance, resilience and vulnerability. Trends Cognit Dis 2011;15:576-584

30. McEwen BS, Bowles NP, Gray JD, et al (2015) Mechanisms of stress in the brain. Nat Neurosci 201518:1353-1363

31. Steptoe A, Kivimäki M. Stress and cardiovascular disease. Nature Reviews Cardiol 2012;9:360-370

32. Raitakari OT, Juonala M, Kahonen M, et al Cardiovascular risk factors in childhood and carotid artery intima-media thickness in adulthood: the Cardiovascular Risk in Young Finns Study. JAMA 2003;290:2277-2283

33. Rosengren A, Orth-Gomer K, Wedel H, Wilhelmsen L. Stressful life events, socia support, and mortality in men born in 1933. Br Med J 1993;307:1102-1105.

34. Carroll D, Ginty AT, Der G, Hunt K, Benzeval M, Phillips AC. Increased blood pressure reactions to acute mental stress are associated with 16-year cardiovascular disease mortality. Psychophysiology 2012;49:1444-8

35. Uthman OA, Hartley L, Rees K, Taylor F, Ebrahim S, Clarke A. Multiple risk factor interventions for primary prevention of cardiovascular disease in low- and middleincome countries. Cochrane Review 2015; DOI: 10.1002/14651858.CD011163. pub2

36. Ebrahim S, Taylor F, Ward K, Beswick A, Burke M, Davey Smith G. Multiple risk factor interventions for primary prevention of coronary heart disease. Cochrane Review 2011;DOI: 10.1002/14651858.CD001561.pub3
37. Hjermann I, Velve Byre K, Holme I, Leren P. Effect of diet and smoking intervention on the incidence of coronary heart disease. Report from the Oslo study group of a randomised trial in healthy men. Lancet 1981;ii:1303-1310.

38. Ornish D, Brown SE, Scherwitz LW, et al. Can lifestyle changes reverse coronary heart disease? The Lifestyle Heart Trial. Lancet 1990;336:129-133.

39. Haskell WL, Alderman EL, Fair JM, et al. Effects of intensive multiple risk factor reduction on coronary atherosclerosis and clinical cardiac events in men and women with coronary artery disease. The Stanford Coronary Risk Intervention Project (SCRIP). Circulation 1994;89:975-990.

40. The Multiple Risk Factor Intervention Trial Research Group. Mortality after 16 years for participants randomized to the Multiple Risk Factor Intervention Trial. Circulation 1996;94:946-951.

41. Tuomilehto J, Lindström J, Eriksson JG, et al. Finnish Diabetes Prevention Study Group. Prevention of type 2 diabetes mellitus by changes in lifestyle among subjects with impaired glucose tolerance. N Engl J Med 2001;344:1343-50.

42. Diabetes Prevention Program Research Group. Reduction in the incidence of type 2 diabetes with lifestyle intervention or metformin. N Engl J Med 2002346:393-403.

43. The Look AHEAD Research Group. Cardiovascular effects of intesive lifestyle intervention in type 2 diabetes. N Engl J Med 2013;369:145-54

44. Shively CA, Day SM. Social inequalities in health in nonhuman primates. Neurobiol Stress 2014;1:156-63

45. Strandberg TE, von Bonsdorff M, Strandberg A, Pitkälä K, Räikkönen $\mathrm{K}$. Associations of vacation time with lifestyle, long-term mortality and healthrelated quality of life in old age: The Helsinki Businessmen Study. Eur Geriatr Med 2017;8:260-264

46. Charlew ST, Piazza JR, Mogle J, Sliwinski MJ, Almeida DM. The wear-and-tear of daily stressors on mental health. Psychol Sci 2013;24:733-741

47. Bot I, Kuiper J. Stressed brain, stressed heart? Lancet 2017;389:770-771.

48. Welch HG. Questions about the value of early intervention. N Engl J Med 1996;334:1472-1473.

49. Sweeney KG, Pereira Gray DJ, Evans PH. Steele RJF. The doctrine of early intervention. BMJ 1996;313:1097. 